\title{
A sobrevida do fait divers
}

Daisi I. Voget

Resumo: Historias suspensas entre o racional e o desconlaccido, sinteses narrativas do estranho, do "espanto fundamental". A partir de textos selecionados em revistas de duas épocas, Scnhor (1959) e piaui (2006), cujas publicações se distanciam, portanto, quase 50 anos, procura-se pensar sobre a agência cultural dessa sorte de relatos jornalisticos que, em fronteira liverc com a literatura, possucm a catacterística da informação total: são comprcensiveis em si mesmos, têm autonomia de significado e uma curiosa permanência no tempo. Qual a atualidade do fait dirers? Quais questões estéticas ele suscita, cm tcrmos culturais? Que lugar ocupa, ainda hoje, na ficçào social que a mídia torna dominante?

Palavras-chave: Fait divers - narrativa jornalistica- litcratura - experićncia estética

Abstract: $A$ bundle of storics suspended between the rational and the unknown, narrative syntheses of the odd, of the "utmost scare". From a selection of texts issued in magazines from two different periods - Senhor (1959) and piaui (2006) - one tries to reflect on the cultural agency of such joumalistic narratives, located in a boundary-free zone between joumalism and literature, that hold the characteristic of total information: they are comprehensible by itself, autonomous in meaning and retain a curious permanence in time. How does the fait divers preserve its actuality? Which aesthetical questions can be brought up about such texts in cultural matters? What place does it occupy nowadays in the social fiction made clominant by the media?

Keywords: Fait divers - journalistic narratives - literature - Acsthetic experience 
'De Minas para Clouzot' é o título de uma pequena história publicada, em maio de 1959, em Senbor, revista lançada no Rio de Janeiro em março daquele ano, pela Editora Delta, e mantida em circulação, mensalmente, até janeiro de 1964. O pequeno relato é de fato quase uma nota, tão curta que a transcrevo inteira. Aparece logo na página seis - continuação, provavelmente, da cartola 'Sr. \& Cia', uma seção permanente e curiosa, porque de curiosidades:

Ninguém a conhecia na cidade. Foi olhada sem muita curiosidade, prazer, ou rancor: ela era velha. Saltou do trem com a mala. Morreu logo. O padre benzeu o corpo e o encomendou a Deus. A mala ficou no hotel.

Alguém disse a alguém que a velha tinha-se suicidado. Alguém disse a alguém que a velha tinha sido assassinada. Entre uma ou outra morte, a morte natural foi abolida. Os padres são homens da morte. O padre abriu a mala. Que continha dinheiro, jóias e as armas do abortista. O padre excomungou o local do enterro. Quis exumar o corpo, mas a cidade não quis, a cidade fechou-se dentro se si própria, calou sobre o assunto. Ninguém sabe mais nada, ninguém fala mais nada.

Aconteceu em Minas Novas, remanescente do ciclo do ouro, em Minas Gerais, há sete meses atrás.

'Lugar de bandido é em alto-mar' é o título de uma segunda história publicada em novembro de 2006 na página 13 de piauí, revista também lançada no Rio de Janeiro, em outubro daquele ano. Tem um subtítulo, 'Enfermeira sexagenária vira musa da turma da bala', é um tanto mais longa, e mesclarei uma transcrição com um resumo. Começa assim:

O assalto era para ter acontecido na véspera, sexta-feira, 6 de outubro. Estava escurecendo. Maria Dora dos Santos Arbex, de 67 anos, saía de um supermercado perto do - apartamento onde mora, no Flamengo, no Rio. Foi ali o primeiro diálogo com o bandido:

- Ô tia, me dá o celular.

- Está sem crédito.

- Vai me dar o celular.

- Vou pensar no teu caso. 
Segue o relato: Maria Dora diz haver reconhecido no homem alguém que perambulava costumeiramente por ali, e ela simplesmente se afastara. No sábado seguinte, ela passeava seu cào lgor, e o mesmo homem a abordou novamente. Pediu-she o cachorro, ela disse não; pediu-lhe a bolsa, ela disse não. Nessa altura, o homem, que se chamava Alexandre Cardoso Pereira, o Nem, começou a falar alto, sacou um canivete e deu pisões nos dedos do pé de Maria Dora. Ela sugeriu tirar ela própria o dinheiro da bolsa, remexeu nela e de lá sacou um revólver. Acertou-o na mão. 'Não matei porque não quis', disse, depois, Maria Dora.

Seguem, no relato, a história e as histórias de Maria Dora. Enfermeira, quatro filhos, fez curso de tiro -- quando o instrutor mandava acertar em ponto não-letal, ela mirava na testa. Depois de atirar em Nem, este saiu correndo e ela foi para casa, onde a polícia chegou na seqüència. Maria Dora não tinha porte de arma, o 38 era da filha. Em 23 de outubro de 2006, recebeu na Càmara Municipal do Rio uma medalha pelo seu feito. O conteúdo do discurso, por ocasiào da entrega da medalha, termina a história: Maria Dota defendeu uma severa política de controle da natalidade e sugeriu que bandidos sejam confinados em navios e mandados para alto-mar'.

Há, sem dúvida, diferenças de tratamento em relação aos protagonistas dessas duas histórias; a de piaui nomeando rigorosamente a todos, a de Senbor, deixando seus personagens no anonimato. Mas também fica logo clara nas duas histórias, ou ao menos no modo como são contadas - em sua ficção - a sua condição de informaçào total. Primeiramente, no que diz respeito à ficcionalidade, acompanho Jacques Rancière (2005: 58) na percepção de que o real precisa ser ficcionado para ser pensado:

Não se trata de dizer que tudos é ficção. Trata-se de constatar que a ficção da era estética definiu modelos de conexão entre apresentação dos fatos e formas de inteligibilidade que tornam indefinida a fronteira cntre razão dos fatos e razão da fiç̧ão |...]. Escrever a história e escrever histótias pertencem a um mesmo regime de verdade. Isso não tem nada a ver com nenhuma tese de realidade ou irrealidade das coisas.

Em seguida, no que diz respeito à condição de informaçào total, há uma similaridade na estrutura ficcional dessas duas histórias. 
Ambas são, de algum modo, imanentes, compreensiveis em si mesmas. Contêm em si todo o seu saber e se elaboram sobre uma dupla notação, uma relação de desdobramento interior à ficção - a velha senhora morta era afinal uma fazedora de abortos; a indefesa senhora assaltada enfrentou. o assaltante a bala -, características, enfim, que Roland Barthes (1977: 263-276) assinalou, no início dos anos 1960, como sendo as do fait divers.

Por que se deter ainda uma vez nessa modalidade de textos? Antes de mais nada, porque, distanciados um do outro por quase meio século, os dois textos trazidos como exemplo brilham, com sua tópica aproximada, em páginas curiosamente parecidas de das duas revistas: editadas em colunas paralelas, nas páginas iniciais, sem fotografias, sem legendas e escritas num modo em que linguagem e formato fogem dos padrões textuais que, justamente nesses 50 anos, se fizeram padrão no jornalismo brasileiro. Ainda por isso, e em seqüência, porque, situáveis no cruzamento do jornalismo com a literatura, eles parecem atravessados de múltiplas temporalidades, múltiplas memórias, e ainda capazes de suscitar questões estéticas no campo da cultura, ao se apresentarem como prováveis desvios na ficção social que a mídia torna dominante.

Uma pergunta central se fará aqui a esses textos, no que diz respeito a sua permanente atualidade ou, por precisão, a sua permanência. O que preserva a vitalidade cultural desses textos, em qual lugar da profusão informativa? Essa pergunta será algumas vezes desdobrada. Começo por uma leitura de caráter mais descritivo dos dois textos, a partir, essencialmente, das reflexões propostas por Barthes, que os definiu explicitamente como literatura. Em seguida, procuro situar o fait divers, no cruzamento da arte com o jornalismo, em sua assimilação peculiar do anônimo e do indizível. Num terceiro momento, a pergunta voltará para o tempo/lugar da permanência do fait divers, com o recenseamento de algumas respostas possiveis.

De partida, é notável a coincidência temática entre essas duas histórias, cada qual com sua personagem idosa em primeiro plano. Se à primeira leitura essa sincronia se sustenta sobre a casualidade, há, no entanto, um causalidade igualmente coincidente em curso, que faz cada uma das histórias ficar atraente para publicação e tornando-as, ambas, nitidamente fait divers. Barthes (ibidem: 275) apontou dois tipos primordiais de articulação imanente nessa sorte de textos: a causalidade aberrante e a coincidência cumulada, sendo que a cau- 
salidade 'é incessantemente submetida à tentação da coincidência", $e$, inversamente, 'a coincidência é aí incessantemente fascinada pela ordem da causalidade'.

Nas histórias publicadas por Senhor e por piani, assoma uma primeira causalidade simples, aferiva: a vulnerabilidade da velhice e seu poder dramático. A senhora desconhecida que morre solitária na cidade pequena, a velhinha com seu cachorro que leva pisões nos dedos dos pés ao ser assaltada numa manhã de sábado. Segue-se cntão, nos relatos, a perturbação dessa causalidade, na medida em que a vulnerabilidade se revela enganosa. Soma-se, a isso, cssa sortc de cúmulo, de a mala da velha senhora solitária, uma vez morta $\mathrm{c}$ enterrada, revelar, afinal, uma aborteira; que o assaltante agressivo e, ao final, todos os infratores existentes, se tornem vítimas potenciais dos projetos da velha senhora.

Nos dois textos, há uma ênfase deslocada, no interior mesmo da causalidade, para um estereótipo em torno da 'velha' ou da 'senhora idosa'. Seria mesmo uma espécie de lugar-comum discursivo, um topos que carrega consigo, na memória, uma idéia de fragilidade, vulnerabilidade, talvez até de abandono. Ocorre que cssas mulheres rematam a causalidade ao seu absurdo, ao revelaram comportamentos que parecem ferir a imagem do estereótipo. De repente, crescem ao revés pela ação que realizam, ou seja, enchem-se de energia c ć como se ganhassem estranha juventude.

Ernst Robert Curtius (1996: 148-152) reuniu uma variada e alentada fileira de exemplos da presença do topos da 'mulher sobrenatural que reúne em si a velhice e a juventude', desde Homero a Balzac, mostrando as relações entre a mentalidade arcaica c a tópica literária. A esse topos associa-se um tema como o aborto, culturalmente carregado de controvérsia, e a reação fria e calculada da scnhora, diante dos ao mesmo tempo banais e agressivos pisões no pé.

Desse modo, em seus desdobramentos internos, o fait dirers opera pela ordem do inexplicável que se inscreve na experiència ordinária do mundo - uma ponta de insondável (natureza?) no círculo da cultura. Mala de idosa morta tinha instrumentos de aborto, velhinha põe em fuga e fere assaltante a bala - parece haver uma distância lógica, como percebeu Barthes (op. cit.: 272), entre a figura frágil da senhora idosa $c$ aquilo que com ela se associa, o aborto, a arma de fogo. 
Dois percursos diferentes assim se fundem, na ficção, em um único percurso, jogando a velha e o aborto, a velha e a arma num mesmo domínio. Paralelamente, os estereótipos invertem de situação, pelo movimento do cúmulo (ibidem: 273). Não apenas se descobre uma aborteira (logo, pela lei, uma criminosa), como essa aborteira era uma pobre velhinha morta; não apenas um assaltante é ferido a bala, como quem dá o tiro é uma senhorinha assaltada.

Ingressa-se, por esse percurso, numa zona ambígua onde o acontecimento é feito em signo. Signo cujo conteúdo é, no entanto, incerto, como diz ainda Barthes (ibidem:275), ao associar o fait divers definitivamente ao campo da realização literária:

Encontramo-nos aqui, se se quiser, não num mundo do sentido, mas num mundo da significação; este estatuto é provavelmente o da literatura, ordem formal na qual o sentido é ao mesmo tempo apresentado e iludido: e é verdade que o caso do dia é literatura, mesmo que essa literatura seja considerada má.

A autonomia desse sentido já atribui um certo caráter de durabilidade aos relatos, tomados em si mesmos, em sua imanência. A história da morte da senhora com sua mala, numa cidade pequena e interiorana (e as derivações possíveis em torno da atitude do padre e do silêncio da cidade), é perfeitamente compreensivel e pertinente em si mesma, cinqüenta anos depois, assim como deverá ser a outra história, a da senhora reativa, daqui a outros tantos. Portáteis, esses relatos sustentam sua força no tempo, de certa forma suspensos entre o racional e o desconhecido, formas condensadas do estranho, sintomas do 'espanto fundamental' (ibidem: 271).

Embora a atualidade seja uma das razões da existência do jornalismo, esse presente imediato ganha uma potência, um devir, à medida em que os textos publicados operam como sintomas de época. Alguns textos associados ao jornalismo, e o fait divers situa-se entre eles, ganham, por isso, outra sorte de durabilidade, porque se inscrevem na ordem da memória - uma organização impura, uma montagem, como afirma Georges Didi-Huberman (2000: 39). É importante, nesse caso, delimitar uma noção precisa de acontecimento, ao qual se toma não como fato, mas como cruzamento de itinerários possiveis. Voltar aos acontecimentos é, assim, procurar pelos itinerários que os atravessam, numa convocação e interrogação à memória (não 
ao passado), pois é ela que humaniza e configura o tempo (idem, ibidem).

Um primeiro sintoma ineludivel é a aceleração do tempo e a compressão do espaço entrevistas na diferença entre os lapsos temporais, dos acontecimentos à publicaçào da primeira e da segunda história. O primeiro acontecimento, de 1959, teria levado sete meses para chegar à revista. Ocorreu numa cidade pequena no interior de Minas e o tempo que decorre até sua inscrição em Senhor; talvez por coincidência, é indício de uma outra relação com a espacialidade: em 1959, as distâncias eram mais longas, o mundo parecia maior. A segunda história é publicada já na ediçào no mês subseqüente ao ocorrido no Rio (cidade de produção das duas revistas, aliás). A história era conhecida, os jornais haviam noticiado as peripécias de Maria Dora e sua condecoração.

Numa perspectiva mais ampla, desenha-se a necessidade de repensar a própria sobrevida do fait divers, como estratégia de relato. Assimilado à cultura do jornalismo, a sobrevivência dessa modalidade de textos, que mantém sua atualidade como gênero, remete à reflexão sobre o lugar que ele ainda ocupa no interior da comunicação, e sobre o material e as percepçôes que ele mobiliza.

Em sua origem francesa, o fait dirersé associado às 'nouvelles à la main, anedotas que se destacavam da vida prática, pelo lado insólito e divertido', e publicadas nas gazetas do século XVII (Alencar, 2007). Há algo de fait divers, também, nos primórdios da notícia criativa norte-americana, nos relatos romanceados que tiveram seu auge na segunda metade do século XIX. A princípio, a notícia criativa era considerada equivalente à imprensa de entretenimento, e 'os seus assuntos eram acontecimentos curiosos, de interesse humano, fatos menores contados de forma leve e descontraida (aquilo que o jornalismo anglo-saxônico chama featurer)' (Fontcuberta, 2002: 70). O frit divers poderia, assim, integrar a grande variedade das notícias de interesse humano, que apelam fundamentalmente à emotividade do leitor (ibidem: 69) e que dispõem de maior liberdade em termos formais.

A palavra francesa seria traduzivel, de forma direta, como feito ou acontecimento diverso. Fail, do latim fatum, participio passado de facere, fazer; divers do latim diversus, o que se separa, diverge, diverte. Aqui, a curiosa relação entre o divergir, tomar rumo diverso, e o divertir, que poderia, então, remeter ao desvio da ordem. E o que mais seria o fait divers? Talvez justamente esse desvio, no qual as coisas rompem a ordem e vertem diferente, divertem. 
Para nós, em nossos dias, histórias que podem ser reconhecidas como fait divers não são estranhas ao noticiário e a descrição de suas características consta mesmo dos manuais de redação dos jornais. Talvez porque sua imanência, como já Barthes ressalvava, não implica um conteúdo estranho ao mundo. Ao contrário. As extravagâncias, os raptos, roubos, agressões, violências, remetem sempre ao humano e sua história, seus fantasmas, seus medos. Seu conhecimento, porém, é sempre como uma dobra, elaborado em gesto analítico por aquele que comenta o fait divers. Em si mesmo, ele é assim um texto breve e total, no que se assemelha ao conto, mas sua totalidade não é totalizante, e de fato o seu fim narrativo escapa, entre o racional e o desconhecido.

Dentro das quatro funções sociais chave que Fontcuberta (ibidem: 28-30) aponta para o jornalismo (informar, formar, distrair e tematizar), o fait divers parece conjugar, enfaticamente, as três últimas. Forma, na medida em que põe em circulação referenciais simbólicos que mobilizam noções como os de papéis sociais e relações do cotidiano; distrai, como elemento próprio do que é desvio; e tematiza, porque inscreve os temas na agenda da opinião pública.

Quanto a informar, essa sorte de relatos retém, é claro, traços informativos, mas não são propriamente o que chamaríamos notícias, pois preponderam neles o curioso e o extraordinário, mais que a informação. Anabela Gradim (2000: 94), em seu Manual de jornalismo, enfatiza o caráter de distração e de exemplaridade, ligados ao conteúdo arquetípico do relato. O fait divers, considera ela, 'é a pequena notícia de interesse humano exemplar que apela ao lado voyeur e um pouco mórbido de todos os leitores'(idem, ibidem).

Ana Maria de Alencar (op. cit.) aponta o efeito de exemplaridade que os faits divers adquirem, 'tornando-se uma das múltiplas formas de agregação tribal' - numa expressão de Michel Maffesoli. Segundo Ana Maria, 'Do acontecido ao narrado, do narrado ao comentado, o caso vai se espalhando e vira assunto de discussões acirradas, através das quais se opina, se toma partido, se julga' em torno de assuntos nem sempre autorizados, como a morte, a violência, o sexo, as leis e as suas transgressões.

A peculiaridade do fait divers também foi considerada, por Luiz Gonzaga Motta, a partir dos mecanismos envolvidos na relação entre o real e o simbólico. Ele observa que nessa sorte de textos o jornalista tem maior grau de liberdade na seleção da informação e no tratamento do texto, de modo que também a subjetividade é ali melhor tole- 
rada. Entre outros recortes teóricos, Motta recorre a Elisabeth Bird e Robert Dardene para contemplar a hipótese de que as noticias, inclusive as de interesse humano, atuam como mito. Mais que informação, elas 'oferecem tranqüilidade, familiaridade, fornecem respostas verossímeis a perguntas desconcertantes' (Motta, 2002: 317). Nessa perspectiva, tais notícias se vincula a uma prática cultural antiga, a de contar histórias, e, como tal, 'constroem totalidades significativas a partir de acontecimentos dispersos' (ibidem).

Esse vínculo ao círculo da cultura remete à sugestào de Sigmund Freud (Apud Damisch: 1984, 12) acerca da constituição do que ele denominou de reservas naturais, das quais também a arte participaria a seu modo. As reservas naturais sào os locais em que se perpetuaria o estado primitivo ao qual o homem teve que renunciar para que se instaurasse a cultura. De fato, a idéia é a dos parques em que a natureza é preservada em sua diversidade, sem as alteraçòes radicais provocadas pela agricultura, pela indústria, pelas comunicaçòes - esses artificios da cultura.

A criação do reino psíquico da fantasia tem, segundo Freud, paralelo na instituição das reservas naturais. Nesse reino, subtraido ao princípio da realidade, o homem pode usufruit de uma liberdade de que já não dispõe na vida real. Hubert Damisch (op. cit. 13) bem observa que essas reservas possivelmente se limitem à formação, dentro do próprio círculo da cultura (e, portanto, ainda longe da natureza), de um certo número de 'ilhas de orden (ou talvez de desordem?)'.

É tentadora a idéia de associar o conceito das reservas naturais, onde tudo deve crescer e se desenvolver à vontade, no universo do fait divers e, mais ainda, às colunas verticais en que revistas como Senhor e pian reúnem esses relatos que, de comum, têm a variedade (afora serem bem redigidos). É a composição de um fluxo de desvios, o que já sugere um parodoxo.

Essa posição refrata uma outra estranha tradição do fait diners, relacionada ao espaço onde ele se materializa. Nas revistas brasileiras, é atualmente rara essa sequêencia inicial de 'notas' redigidas em formato criativo e paginadas em colunas, sem fotografias - apenas ilustrações. Essa forma, em si mesma, é atravessada por temporalidades - pode-se mesmo ver nessas páginas de piraui uma tessonância da experiência editorial de Senhor:

Em Senbor, a seção de maio de 1959, por exemplo, en que se publica a história da velhinha aborteira, abre com um texto em 
tradução, um excerto de Cyrano de Bergerac, Ato II, Cena 4. Poema narrativo, 'Pastéis de Cyrano de Bergerac' é de fato uma receita culinária em três estrofes de cinco linhas. Comment on fait les tartelettes amendines (Maneira de fazer as tortinhas de amêndoas doces) ensina a fazer tartelettes passo-a-passo, em tradução cuidadosamente rimada de Carlos Porto Carreiro. Em coluna, aparece no alto a versão em francês e, embaixo, em português. Depois, seguem relatos sobre as recomendações de um certo Professor Rego Barros, da Universidade da Bahia, para dormir melhor fazendo carinho, e sobre a contaminação radioativa de alimentos da Bacia Amazônica, seguindo informação da Sociedade Americana de Química.

Essas páginas de Senbor em que foi publicado o relato sobre a velha senhora morta são, pois, um tour por curiosidades, algo como um radar, um panorama de relatos de situações e eventos ocorridos em quaisquer partes, e o que os torna estranhos é virem em fieira, um após o outro, sem assinatura, em estreitas colunas verticais. São duas colunas para cada meia página (em seção também vertical), ou seja, cada página tem, em seu lado externo, duas colunas estreitas; de alto a baixo, com pequenos relatos ilustrados a bico-de-pena. $\mathrm{Na}$ outra metade longitudinal da página, a metade interna, próxima à dobra, a mancha de texto ocupa colunagem dupla, em que aparecem artigos assinados - nesta edição, a de número três, Darcy Ribeiro, Luiz Lobo e Mario da Silva.

Em piaui, as histórias que acompanham a de Maria Dora dos Santos ocupam seis páginas, distribuídas em quatro colunas por página. A primeira descreve como será a festa de posse do segundo mandato do presidente Lula. Depois, o caso do escritor Paulo José Cunha, autor da Grande Enciclopédia Internacional do Piauiês. Há ainda as histórias do Clube Galo, o maior centro de rinhas de Salvador.

Define-se, nessa diversidade, algo como a silva de varia lección, esse conjunto de textos que pertence ao gênero das enciclopédias e miscelâneas, cultivado desde os gregos até a Idade Média Latina. Mas também reserva natural, em que se preserva, no contemporâneo, a ambigüidade do racional e do irracional, do inteligivel e do insondável. O conteúdo incerto do fait divers, ilha em que o sentido parece às vezes escapar ao artifício e remeter à natureza, é espacialmente 'organizado' pelas colunas, onde retorna ao círculo da cultura.

Uma possibilidade complementar de pensar a sobrevida do fait divers, como estratégia ficcional, está, talvez, em sua associação à 
conformaçào do regime estético das artes. O regime que, na leitura proposta por Rancière (op. cit.: 47), tornou o anónimo não só capaz de se fazer arte, como o fe\% depositário de uma beleza especifica. Ranciére pensa as artes dentro de três regimes históricos, o ético, o poético ou representativo e o estético. Este último, que caracteriza o olhar sobre a arte que é geralmente chamado de modernidade estétca, identifica as coisas da arte por pertencerem a um regime especifico do sensivel:

Esse sensivel, subtraido a suas conexōes ordinárias, é habitado por uma potência heterogênea, a potência de um pensamento que se tornou ele proprio estranho a si mesmo: produto idêntico ao não-produto, saber transformado em não-saber, logos idêntico a patbos, intenção do inintencional ctc. (Rancière, op. cit.: 32.)

O que para o filósofo é a chave de identificação de todo o pensamento estético moderno e, por extensão, do momento de formação de uma humanidade especifica e de um modo específico de relação com o antigo, ajuda a pensar o lugar do fait divers. Este pequeno objeto em que coabitam, afinal, temporalidades heterogêneas: a reprodução generalizada da cultura de massas e o acontecimento do anônimo, do pormenor; a sedimentação de laços de comunidade e a assimilação de uma idéia de desvio, estranhamento, ruptura.

Porque o fait divers, poder-se-ia dizer, circula ambiguamente entre duas práticas. Circula e é assimilado pelas práticas e pela cultura do jornalismo, com sua agência sobre os novos modos de viver em meio à proliferaçào das imagens, palavras e mercadorias - noçào sintonizada, aliás, com um projeto em que as artes são situadas como modo de vida em comunidade. Mas circula, também, por seu jogo com a literatura, entre as práticas de uma arte que, naquele momento de definiçào de um regime estético, passa a ser designada no singular c clama por autonomia, propondo-se romper a relação que mantém como edificadora da vida em comum.

Foi na literatura que primeiro de manifestou o tegime estético das artes, em supressão ao sistema da representação, em que a dignidade dos temas comandava a hierarquia dos gêneros de representação (ibidem: 47). É a literatura que abre espaço, pela primeira vez, para que uma época e uma sociedade sejam lidas nos gestos, vestimentas 
e modos de ser de indivíduos quaisquer. Abre-se aí um novo regime estético, que permite e instaura 'a glória do qualquer um' (ibidem: 48).

A literatura assim inicia, no século XVIII, um programa que substitui os grandes acontecimentos e personagens pela experiência dos anônimos, pelos detalhes das vidas ordinárias, reconstituindo o mundo a partir de seus vestígios: $O$ ordinário, o pequeno, o banal tornam-se belos, em Balzac e Tolstoi, como rastros do verdadeiro. Uma figura sem dúvida fantasmagóriça do verdadeiro, na medida em que este é arrancado de sua evidência.

Se foi no âmbito do jornalismo que, inicialmente, ocorreu o processo laicizador da noção de literatura, a qual passou a integrar também os textos em prosa publicados nos jornais, foi por essa jovem literatura que a arte, que se autonomizava, se inscreveu, primeiramente, nas páginas dos periódicos, criando zonas em que o objeto jornalístico e o objeto artístico convergiam, no sentido de se manifestarem um sobre o outro, em sobrechoque.

Não teria sido, assim, a possibilidade técnica, com suas grandes tiragens e circulação por mais largas distâncias, que fez o anônimo ser arte; foi, antes, o tema do anônimo que se tornou, sintomaticamente, qualificado para a arte, arrastando formas como o fait divers, o folhetim, a crônica (que qualifica o banal) e parte da reportagem (a essa que chamam de literária ou narrativa) para um novo estatuto. $O$ fait divers, ao lado e em relação a outros textos; pode ser lido como sintoma; como tal, se faz como complemento a toda ficção (seja considerada jornalística ou literária) estruturante de uma cena pública.

Finalmente, é significativo desviar o olhar para outro lugar uma bienal de artes, um lugar em que há uma sucessão de histórias, ou de pequenas histórias, ou de não-histórias, não obstinadamente distinta, em termos de disposição, das colunas de features das revistas -, e ali encontrar um... fait divers. Uma vídeo-performance de $4 \mathrm{~min} 30 \mathrm{~s}$ apresentada por Narda Alvarado (Bolívia) na $27^{a}$ Bienal de Artes de São Paulo, intitulada Verde oliva, era ao mesmo tempo uma intervenção urbana, uma performance, um vídeo (quem sabe uma reportagem em vídeo sobre uma performance?).

Uma fila indiana de militares em fardas verdes marcha, detém os carros de uma avenida, atravessa a pista e ali permanece, em posição de guarda. Os carros começam a formar filas duplas, nas duas direções do tráfego, enquanto os militares, segurando cada qual um pratinho, comem tranqüilamente uma azeitona. $\mathrm{Na}$ seqüência, ainda em fila e em marcha, saem de cena. 
A causalidade nesse episódio é típica do fait divers. Os militares interditam uma avenida em La Paz. Alguma ação repressiva? Não, vieram comer uma azeitona. Que o que comem seja da cor de suas fardas é, já, o cúmulo da coincidência. Outras 'coreografias sociais e rituais' de Alvarado (assim são definidas por Rosa Martínez, que entrevistou a artista para a edição do Guia da $27^{a}$ Bienal de São Paulo, 2006) trazem uma ficção similar. Del Atlántico con amor; por exemplo, encena uma cerimónia militar de boas vindas a um balde de água trazido do Brasil. Sào performances que, como definiu a artista, se inscrevem num 'paraíso imperfeito onde nada é impossivel' (27 $7^{\mathrm{a}}$ Bienal, 2007: 188).

Se 'a escrita é a arte de levantar questões e não de lhes responder, ou de as resolver', conforme dizia Barthes (1982: 15), já ai assome a relação com a arte contemporânea ou pós-moderna - que também quer mais propor questões, do que respondê-las. A todas resta por fazer o mapa do inexplicável contemporâneo - não como o representa a ciência ou a história do "passado", mas um mapa tecido de memórias, heterogêneas, sintomáticas, memórias inclusive do senso comum e seus reveses.

Finalmente, é possivel ainda tecer uma última consideração sobre a vitalidade das histórias que reconhecemos como fait divers. Por compartilharem traços que são atribuídos às artes (f fnalidade comunicativa que transcende o imediato e que, retirada do contexto pragmático, se estrutura de modo autônomo), esses textos operam simultaneamente como complemento e como desvio, na ficção social que a mídia torna dominante.

Os faits divers situam-se, por paradoxo, no interior da comunicação massmidiática e na resistência a ela. Por conseguinte, esses textos são fulgurações da comunicação que operam, no entanto, seguindo uma reflexão de Mario Perniola (2006), contra a comunicação massmidiática, caracterizada pela homogeneização e pelo fluxo. Tal imagem permite que nela se veja não apenas uma explicação para a sobrevida do fait divers, como também a complexidade do lugar do jornalismo na esfera da cultura. 


\section{Referências}

ALENCAR, A. M. de. O que é o fait-divers ? Considerações a partir de Roland Barthes. In http://www.letras.ufrj.br/ciencialit/docente/trabalhos/ana_alencar_fait_divers.html Acesso em 3 abr 2007.

BARTHES, R. Estrutura do caso do dia. In Ensaios criticos. Lisboa: Edições 70, 1977. p.263-276. (Coleção Signos 11) - O grão da voそ: Lisboa: Edições 70, 1982. (Coleção Signos 37)

CURTIUS, E. R. Literatura européia e idade média latina. São Paulo: Hucitec: Edusp, 1996. (Linguagem e Cultura 21)

DAMISCH, H. Artes. In Enciclopédia Einaudi, vol 3. Lisboa: Imprensa Nacional, Casa da Moeda, 1984.

DIDI-HUBERMAN, G. Ante el tiempo. Buenos Aires: Adriana Hidalgo, 2006.

FORTINI, F. Literatura. In Enciclopédia Einaudi, vol 17. Lisboa: Imprensa Nacional, Casa da Moeda, 1989.

FONTCUBERTA, M. de. $A$ notícia: pistas para compreender o mundo. 2 ed. Lisboa: Editorial Notícias, 2002.

GRADIM, A. Manual de jornalismo. Covilhã, Portugal: Universidade da Beira Interior, 2000.

MOTTA, L. G. Teoria da notícia: as relações entre o real e o simbólico. In MOUILLAND, Maurice; PORTO, Sérgio Dayrell (org.). O jornal: da forma ao sentido. 2 ed. Brasília: Editora Universidade de Brasília, 2002. p. 305-319.

PERNIOLA, M. Contra a comunicafão. São Leopoldo, RS: Editora Unisinos, 2006.

RANCIÈRE; J. A partilha do sensivel: estética e política. São Paulo: EXO experimental org; Ed: 34, 2005.

VEYNE, P. Cómo se escribe la Historia. Madrid: Alianza, 1984.

$27^{\mathrm{a}}$ BIENAL DE SÃO PAULO: Como viver junto: Guia/ [editores Lisette Lagnado, Adriano Pedrosa]. São Paulo: Fundação Bienal, 2006. 